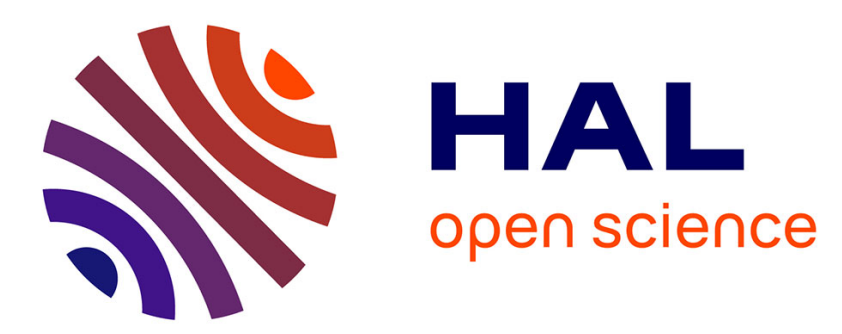

\title{
Nou tout an dlo-la: a swimming-based physical activity promotion program
}

Sophie Antoine-Jonville, M-L Lalanne-Mistrih, B Tressières, R Monjo, Olivier Hue

\section{- To cite this version:}

Sophie Antoine-Jonville, M-L Lalanne-Mistrih, B Tressières, R Monjo, Olivier Hue. Nou tout an dlola: a swimming-based physical activity promotion program. Public Health, 2013, 127, pp.967 - 969. 10.1016/j.puhe.2013.07.002 . hal-01528782

\section{HAL Id: hal-01528782 \\ https://hal.science/hal-01528782}

Submitted on 29 May 2017

HAL is a multi-disciplinary open access archive for the deposit and dissemination of scientific research documents, whether they are published or not. The documents may come from teaching and research institutions in France or abroad, or from public or private research centers.
L'archive ouverte pluridisciplinaire HAL, est destinée au dépôt et à la diffusion de documents scientifiques de niveau recherche, publiés ou non, émanant des établissements d'enseignement et de recherche français ou étrangers, des laboratoires publics ou privés. 
Nou tout an dlo-la: a swimming-based physical activity promotion program

S. Antoine-Jonville ${ }^{1}$, M.L. Lalanne-Mistrih ${ }^{2}$, B. Tressières ${ }^{2}$, R. Monjo ${ }^{1,3}$, O. Hue ${ }^{1}$

1. Adaptation to Tropical Climate and Exercise Laboratory, EA3596, University of French West Indies, Guadeloupe, France

2. Clinical Investigation and Epidemiology Center, INSERM 802, Guadeloupe, France

3. Regional Swimming League, Guadeloupe, France

CORRESPONDENCE: Dr. Sophie ANTOINE - JONVILLE

Laboratoire ACTES, Université des Antilles et de la Guyane

BP 250

97157 POINTE A PITRE Cédex

GUADELOUPE

s_antoine@ymail.com_ sophie.jonville@univ-ag.fr

Tel: (+ 590) $590483175 \quad$ Fax: (+ 590) 590483179

FUNDING: Nou tout an dlo la was funded by the French Ministry of Sports and Health and also received financial support from the European Union Structural Funds.

We warmly thank all the actors: participants, physicians, sports educators, and program managers (Elsa Suares and Priscia Hespel) for their great involvement and enthusiasm.

COMPETING INTEREST: None. 


\section{INTRODUCTION}

Guadeloupe is a Caribbean archipelago. The coast proximity has been associated with improved health and well being. ${ }^{1}$ It provides easy access to safe public beaches and to several private water-based activities. A small proportion only of the elderly are able to enjoy these places for physical activities. Many others, in particular those with chronic diseases, are faced with limited, poorly adapted or expensive choices for these activities. Although physical activity is often recommended as a self-management strategy for improving or controlling many chronic disease, these community members are thus impeded to move from a pre-action stage to an action maintenance stage $^{2}$ for increase of physical activity in such a context. Under the leadership of the regional swimming league, we federated a multidisciplinary team of professionals and patient representatives to design a project to increase patients'opportunities for physical activity.

Nou tout an dlo-la, which in Creole means " all together into the water", was designed to encourage short- and longer-term participation in physical activities through the development of personal skills, self-confidence, and social networking. Participants who joined received 10 weeks of access to professionally supervised swimming lessons and other water activities.

To maximise equal opportunities for patients with chronic diseases who wanted to join the program, independently of their condition, we communicated through 2 of the major local media (1 radio and 1 newspaper) in Guadeloupe. Only basic information was given, but a phone number was provided for interested persons seeking more information. During this phone interview, we answered questions and emphasized the main principles of the program, the eligibility requirements ( $>50$ years, low physical 
activity), and the program features that facilitated participation (transportation, time schedule, practice location). Participants were primarily women (140 out of 160 patients) and most had moderately incapacitating chronic diseases, like diabetes and hypertension. They were invited to participate with a caregiver or relative, but only 39 patients used this opportunity, for a total number of 199 participants. Attrition was moderate with $80 \%$ of patients attending regularly up to the end of the 10 -week period. See Figure 1 for program design and participant flow.

We first defined and tested the evaluation and communication procedures. We then conducted 5 intervention periods each lasting 10 weeks. During each period, several practice sites were open, with a total of 12 sites and at least 1 qualified sports educator per site involved in the program.

Each participant followed the same schedule during the intervention period: 2 swimming sessions (1 hour each) the first week and 1 swimming session plus another 2.5-hour session of sailing or kayaking the following week, with this alternating pattern then repeated for a total of 5 times. The only cost to the participants was a consultation with their regular physician, who filled out a form specifying any functional limitations that the sports educator would need to take into account. This original form we developed allows the respect of medical secret while transmitting participant's restrictions to physical activity participation due to health status. 


\section{QUALITY OF LIFE (QOL)}

We administered QOL and physical activity questionnaires before the intervention

( $\mathrm{T}$ ) and after the 10-week period of facilitated access to water-based physical 0

activities (T10w). Another 10 weeks after their last practice session (T20w), participants were invited to a maintenance session, in which they again responded to the same questionnaires. Informal interviews were also conducted with most actors throughout the program.

QOL was measured with the French abbreviated version of the World Health Organization Quality of Life (WHOQOL-BREF) questionnaire. The WHOQOLBREF is a 26-item instrument including 4 domains of quality of life: physical health, psychological health, social relationships, and environment. It has good psychometric characteristics, ${ }^{3}$ and the outcome is a 0-100 score for each domain, with a higher score indicating better QOL. Standard instructions (World Health Organization, 1996) for administration (self report) and scoring were followed. ${ }^{4}$ This was also the case for physical activity assessment. A general linear model with repeated-measures was used to compare changes in QOL scores over time. For all variables, a significance level of $5 \%$ was chosen and statistical analysis was carried out using SPSS v.20 software (SPSS Inc, Chicago, IL, USA).

The greatest QOL change in patients, although non-significant $(\mathrm{p}=0.095)$, was observed for the physical health score: from $47.1 \pm 16.7$ (mean \pm standard deviation) at To to $49.3 \pm 18.9$ and $45.6 \pm 22.1$ at $\mathrm{T} 10 \mathrm{w}$ and $\mathrm{T} 20 \mathrm{w}$, respectively. The other dimensions of the WHOQOL-BREF did not change significantly over time (all $\mathrm{p}>0.154$ ), and all scores were low with $62.8 \pm 17.0,54.4 \pm 21.9$ and $17.7 \pm 18.7$ at baseline for 
psychological health, social relationships and environment, respectively. 


\section{PHYSICAL ACTIVITY}

Physical activity was assessed using the short form of the International Physical Activity Questionnaire (IPAQ) administered during individual interview. ${ }^{5}$ It consists of 7 questions about the frequency and duration of physical activity from any source (leisure, transportation, housekeeping, etc.) within different intensity categories during the previous week. Information on time spent sitting was also collected. The scoring system yields an overall score (in MET-minutes/week, a MET being the metabolic equivalent to characterise physical activity intensity as multiples of the basic metabolic rate) and allocation to an IPAQ category (low, moderate, or high level of physical activity). The IPAQ scores, expressed as medians and $1^{\text {st }}$ and $3^{\text {rd }}$ quartiles (because of non-normal distribution) were compared with nonparametric Friedman analysis of variance.

We observed improved swimming skills in all participants. Out of the 77 patients that filled out the IPAQ at all timepoints, the improvement in physical activity was significant $(\mathrm{p}<0.001)$, with 446 [0;809] METs.min/week at To, 876 [480;1335] at T10w, and 765 [240;1485] METs.min/week at T20w. For patients involved from the time of inclusion to the last evaluation timepoint, the physical activity amplitude increased considerably. In comparable populations, low-cost exercise programs based on behavioural strategies report variations of about 200-300 METs.min/week ${ }^{6,7}$ and more stress-inducing settings like exercise-training programs are required to reach greater short-term variations in completers. ${ }^{8}$

The absence of variation in most QOL dimensions reflects no perceived QOL impact of the program. However, we report a trend toward improved perceived physical health. Since the volume of physical activity is associated with changes in QOL, ${ }^{9}$ 
slightly greater increase in physical activity in future programs might be associated with perceivable physical health effects and related improved QOL.

The program also contributed slightly to the structuring of this economic and health sector, as the sports professionals reported an improved ability to safely include patients in regular leisure groups, in particular thanks to a hotline with easy access to a program-affiliated physician and the information given to them on each patient's potential limitations during the activities. In addition, the medical professionals seemed to have greater confidence in the sports sector, as indicated in some of the interviews.

In conclusion, our experience shows that programs based on swimming skills and social networking have a strong potential for health promotion in places with easy access to the sea such as tropical climates. From an experimental perspective, the main limitation of this evaluation was the lack of a control group. We also note that the results are restricted to those patients who were evaluated over the 20 -week period. However, our program shows that a moderate and sustainable increase in physical activity can be achieved under conditions of facilitated access to professionally-driven sports classes in a supportive group setting. The next steps of the program are aimed at decreasing cost through diversification of our resources, strengthening community action, and improving short- and mid-term patient commitment by introducing regular group challenges. 


\section{ACKNOWLEDGEMENTS}

Nou tout an dlo la was funded by the French Ministry of Sports and Health within the context of its experimental program to develop local initiatives for improving the quality of life of patients with chronic diseases. We also also received financial support from the European Union Structural Funds.

We warmly thank all the actors: participants, physicians, sports educators, and program managers (Elsa Suares and Priscia Hespel) for their great involvement and enthusiasm.

\section{DECLARATIONS}

No competing interests

Ethics. The principles of Helsinki declaration, medical confidentiality and anonymity of the participants in the analysis were respected. The local ethics committee gave its approval. The automated treatment of personal information was declared to the adequate national commission (Commission Nationale de l'Informatique et des Libertés). 


\section{REFERENCES}

1. Wheeler BW, White M, Stahl-Timmins W, Depledge MH. Does living by the coast improve health and wellbeing? Health Place 1012;18:1198-1201.

2. Prochaska JO, DiClemente CC. The transtheoretical approach: crossing traditional boundaries of therapy. Homewood, IL: Dow Jones-Irwin; 1984

3. The WHOQOL Group. Development of the World Health Organization WHOQOLbref. Quality of life assessment instrument. Psychol Med 1998;28:551-8.

4. World Health Organization. WHOQOL-BREF. Introduction, administration, scoring and generic version of the assessment—field trial version. Geneva: World Health Organization; 1996.

5. IPAQ committee. Guidelines for data processing and analysis of the International Physical Activity Questionnaire (IPAQ). 2005. Available at: http://www.ipaq.ki.se/scoring.htm. [accessed 14.02.13]

6. Gibson B, Marcus RL, Staggers N, Jones J, Samore M, Weir C. Efficacy of a computerized simulation in promoting walking in individuals with diabetes. $J$ Med Internet Res 2012;14:e71.

7. Martinson BC, Sherwood NE, Crain AL, Hayes MG, King AC, Pronk NP, O'Connor PJ. Maintaining physical activity among older adults: 24-month outcomes of the Keep Active Minnesota randomized controlled trial. Prev Med 2010;51:37-44.

8. Mai KS, Sandbaek A, Borch-Johnsen K, Lauritzen T. Are lifestyle changes achieved after participation in a screening programme for Type 2 diabetes? The 
ADDITION Study, Denmark. Diabet Med 2007;24:1121-8.

9. Nicolucci A, Balducci S, Cardelli P, Cavallo S, Fallucca S, Bazuro A, Simonelli P, Iacobini C, Zanuso S, Pugliese G; Italian Diabetes Exercise Study Investigators.

Relationship of exercise volume to improvements of quality of life with supervised exercise training in patients with type 2 diabetes in a randomised controlled trial: the Italian Diabetes and Exercise Study (IDES). Diabetologia 2012;55:579-88. 
CAPTION

FIGURE 1. Study design and participant flow. 